\title{
Reviews of Resource Assessment on Tidal Current Energy of China
}

\author{
He WU* \\ National Ocean Technology Center \\ Tianjin, China \\ wh_crane@163.com \\ Yang BAI \\ National Ocean Technology Center \\ Tianjin, China \\ minibaiyang@qq.com
}

\author{
Ya-nan WU \\ National Ocean Technology Center \\ Tianjin, China \\ hdwuyanan@163.com \\ Guo-wei WU \\ National Ocean Technology Center \\ Tianjin, China \\ guowei.wu@foxmail.com
}

\begin{abstract}
In the context of global energy crisis and climate change, tidal current energy is one kind of marine renewable energy rich in total resources with little effect on environment and higher TRL and have promising prospects of utilization in the offshore region of China. Although significant progresses have been made in the past decades, the work on the resource assessment affecting its utilization, the impacts of utilization on the environment and so forth still needs further investigation and improvement. This paper is to review the assessment work and main research results of large-scale tidal current energy in coastal region in the Chinese history, summarizing and analyzing the main technical features of assessment methods for tidal current energy. On this basis, the relevant suggestions on surveys and evaluation researches were put forward combining the development situation of utilization of tidal current energy, which can provide scientific references for the utilization tidal current energy in China.
\end{abstract}

Keywords-Tidal current energy; resource assessment; assessment method

\section{INTRODUCTION}

To better deal with the energy crisis and climatic change, solar energy, wind energy, marine energy and various renewable energy sources have attracted extensive attention, especially from the developed coastal countries like the European Union, the United States and Japan [1]. Wherein, tidal current energy is one kind of marine renewable energies with relatively high technology readiness level (TRL) [2] (except the utilization technology of tidal range energy with a dam), reaching Level 8 . The converting technology of tidal current energy is mainly classified into three types of horizontal axis turbine, vertical axis turbine and other type [3]. The above technologies have entered into sea trial period, even into the quasi-commercial power plant demonstration stage.

The same as wind energy, solar energy and other renewable energy sources, tidal current energy has the characteristics of uneven temporal-spatial distribution [4, 5]. Therefore, the changing features of energy resources in favorable region, the assessment on the quality and quantity of resources which can be actually exploited, the forecast of the influence of energy utilization on ocean dynamics and zoology environment, and the performance of necessary assessment and characteristics analysis on tidal current energy are very important fundamental work for facilitating the utilization.

Tidal current energy are very abundant in many sea areas near the coastline with a total length of $32,000 \mathrm{~km}$ in China. For example, the maximum flow velocity of several channels in Zhoushan archipelago can reach $3.7 \mathrm{~m} / \mathrm{s}$ [6], enjoying broad utilization prospects [7]. The survey and preliminary assessment on offshore tidal current energy were implemented from the late 1980s [5, 8], Two important special funds named as "Marine Comprehensive Investigation and Assessment in China (MCIAC)" and "Marine Energy Special Fund (MESF)" were respectively implemented in 2004 and 2010 [4, 9], in which rich observations were obtained, and temporal and spatial variation characteristics of tidal current energy in major channels in China was analyzed. The total potential of this kind of marine energy were preliminarily estimated, and the fundamental state of tidal current energy resource in coastal region of China was basically understood.

This paper is to summarize the data characteristics, methods of resource assessment and main results of previous large-scale survey and resource assessment of offshore tidal current energy in the history in China, and put forward suggestions on the issues of the engineering survey and site selection, turbine motor deign and array optimization of future tidal current energy and other issues related to resources characteristic analysis and assessment study.

\section{ASSESSMENT METHOD FOR ENERGY RESOURCE}

In recent years, both International Electrotechnical Committe (IEC) and European Marine Energy Centre (EMEC) prepared the relevant technical regulations on analysis and assessment of tidal current energy resource [10-13]. China's Marine Standard Committee also established several standard projects, National Ocean Technology Center and Ocean University of China 
together were responsible for compiling the assessment procedures of tidal current energy resources and it has entered into the stage of seeking for opinions. The aforementioned work unified the resource assessment method for tidal current energy to some extent, and provided technical support for the consistency and comparability of the resource assessment results. However, the conversion form and efficiency of the technology of tidal current energy at present are not unified, there are differences in the assessment method for tidal current energy in many aspects. In general, the differences are embodied in two aspects. The first difference is in the basic data to describe the characteristics in assessment, and the second difference is in the theoretical basis for the calculation of total energy potential and concrete calculation formula.

\section{A. Assessment Method for Tidal Current Energy}

1) Assessment based on different data sources

The data sources of assessment on tidal current energy resources can be classified into two types: field measurement and numerical simulation.

It is the immediate way to get the fundamental data by field measurement for the assessment of tidal energy, and several kinds of instruments were used for measuring ocean current, including ADCP, Mechanical Current Meter, Electromagnetic Current Meter etc. Two main ways taken for current measurement are Mooring and Navigation. Between of them, the former is to depict the temporal characteristics of tidal current energy on the measured station while the latter is to get the spatial and temporal characteristics along the ship route. More accurate assessment of tidal current energy will be given using the measured data, hence the conclusion of which is especially fit for the stage of design development of tidal energy in which there have been confirmed for the site selection to deployment or for the stage of preliminary assessment. The numerical simulation of tidal wave is not ripe enough to supply precise current data, and some previous works have been done under this circumstance: For example, Kuang [14] ever combined short-term actually measured tide data with method put forward by Zheng [15] to make preliminary estimation of tidal current energy in the region outside Chengshan Cape. $\mathrm{Wu}$ [16] used tide harmonic analysis and predication to make a new analysis on the resources of tidal current energy in the same region; He [17] did the similar assessment of tidal current energy resources over 10 channels among Zhoushan archipelago, including Xihoumen, Guanmen, Guishanhangmen, etc. Wang [18] made the assessment with measured tidal current for consecutive $26 \mathrm{~h}$ of 5 stations in Gaoting Channel and 8 stations in Guanmen Channel in Zhoushan archipelago.

Because the complex submarine topography leads to complex characteristic of flow field, it is impossible to capture higher resolution spatial characteristics of tidal current energy from field measurement. Therefore, the assessment of tidal current energy resources based on numerical simulation become more and more popular because it can supply enough data to assess the detailed spatial and temporal characteristics of tidal current energy for the whole focused area with a reasonable cost. In addition, this method based on numerical simulation can also be used to forecast the environmental effects caused by tidal turbines. The Standard for Assessment of Tidal Energy Resource published by the EMEC recommends dozens of widely-used models for simulating tidal current. FVCOM, POM, ECOMSED and other ocean models also have been used for resource assessment in China. Wherein, LV [19] used POM circulation model for the first time to conduct analysis and total amount estimation on the tidal current energy resources in the mouth of Jiaozhou Bay. Later, $\mathrm{Wu}$ [20] used ECOMSED model to make preliminary analysis on the tidal current energy resources in Laotieshan channel; $\mathrm{Wu}$ [21], Hou [6], Chen [22], Wu [23] analyzed the characteristics of tidal energy used the same unstructured-grid ocean model FVCOM over Bohai Straits, the channels of Zhoushan archipelago, Xiamen Bay, Qiongzhou Strait, separately.

It should be pointed out that the numerical simulation of tidal current also needs measured data. However, these data are only used for the model validation and are not involved in the computation of tidal current energy. More importantly, the forecasting accuracy of tidal current from ocean model may be not good enough, and large error could take place due to that the power of tidal energy is proportional to the cube of current speed. Therefore, the assessment of tidal current energy based on the numerical simulation is still the auxiliary means to the planning and design of tidal stream farm, and is beneficial supplement of development of tidal current energy.

\section{2) Calculation formula of total resources potential}

The consensus has been basically reached on the calculation formula of flux conservation of tide energy theory in China, that is, the average power of the tidal current energy passing some cross section of water channel.

The specific calculation formula is as follows [19]:

$$
P=\frac{\rho}{2 T} \int_{t}^{t+T} \int_{0}^{L} \int_{-H}^{0}|V|^{3} d z d x d t
$$

where $P$ is theoretical potential of tidal current energy, $t$ is initial moment, $T$ is assessment period (one year), $L$ is width of water channel, $H$ is depth of water, and $\rho$ is seawater density $\left(1025 \mathrm{~kg} / \mathrm{m}^{3}\right)$. Please be noted that this assessment method mainly relies on the tidal current numerical simulation data which is the main basic data of appraisal.

However, the estimation method for exploitable amount of the tidal current energy resources (technology) was still controversial. The estimation method can be mainly classified into the two types as follows: the assessment method based on energy flux and based on dynamic analysis. The method based on energy flux mainly includes FARM [24] method, FLUX [25] method and simple assessment method put forward by Zheng [15]. The method based on dynamic analysis mainly refers to the new method put forward by Garrett and Cummins, [26, 
27] which was generally referred to as "Garrett method". LV [3] pointed out that FARM method has clear calculation thought and it is easy to be comprehend. However, there is a relevant big uncertainty in the realty. The calculation of FLUX is simple, but the determination on significant impact factor (INF) still is largely empirical. Although Garrett method enjoys relatively rigorous theory basis and has a certain practicability, the test on practice of estimation is relatively few. Later, Ross [28-30] made some improvement on the calculation formula of Garrett method.

\section{LARGE-SCALE ASSESSMENT OF TIDAL CURRENT ENERGY IN CHINA}

So far, China has implemented the comprehensive large-scale surveys and assessments on tidal current energy for 3 times (see Table 1). However, due to the differences in data source, assessment formula, section selection (tidal current energy) or representative section length (wave energy) and other factors, the differences, advantages and disadvantages between different assessment results are hard to be compared.

TABLE I. ALL PREVIOUS ASSESSMENT OF TIDAL ENERGY IN CHINA

\begin{tabular}{|c|c|c|c|c|c|}
\hline $\begin{array}{c}\text { Resource } \\
\text { type }\end{array}$ & $\begin{array}{c}\text { Serial } \\
\text { No. }\end{array}$ & $\begin{array}{c}\text { Execution } \\
\text { year }\end{array}$ & Presiding department & $\begin{array}{c}\text { Representative section } \\
\text { of number of water } \\
\text { channel (area) }\end{array}$ & $\begin{array}{c}\text { Theoretical } \\
\text { potential amount } \\
\text { (GW) }\end{array}$ \\
\hline \multirow{3}{*}{$\begin{array}{c}\text { Tidal current } \\
\text { energy }\end{array}$} & 1st time & 1986 & $\begin{array}{c}\text { Department of Water and } \\
\text { Power and State Oceanic } \\
\text { Administration (SOA) }\end{array}$ & 130 & 1.396 \\
\cline { 2 - 6 } & 2nd time & 2004 & SOA & 99 & 0.833 \\
\cline { 2 - 6 } & 3rd time & 2010 & SOA & 10 (area) & 0.556 \\
\hline
\end{tabular}

\section{A. Tidal Current Energy}

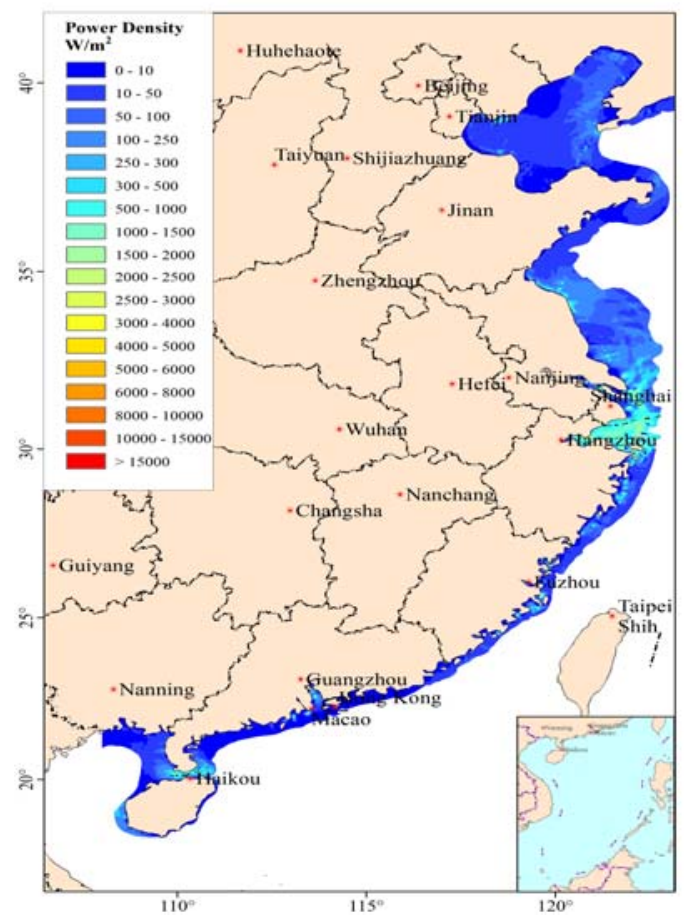

Figure 1. Distribution of average power density of tidal current energy resources in China.

The first large-scale assessment on tidal current energy resources was from the study of Zoning of Marine Energy Resource in Coastal Villages of China(ZMERCVC), in which WANG[5] made statistics on 130 water channels according to the sea chart tide information at that time. The study showed that the average theoretical potential of tidal current energy resources is about $1.396 \mathrm{GW}$ in coastal region of China. The spatial distribution of this kind of energy resources is mostly asymmetry. There are
95 channels which are relatively concentrated in the East China Sea coast with a theoretical average power of 1.096 GW, accounting for $78.6 \%$ of the total amount. The most plentiful region of tidal current energy along the coast of Zhejiang Province with 37 channel, in which the energy potential is $0.709 \mathrm{GW}$, accounts for more than a half of the total amount. In the remaining provincial coastal regions, the average power from Taiwan, Fujian, Shandong and 
Liaoning is about $0.587 \mathrm{GW}$, being $41.9 \%$ of the total amount.

The second large-scale assessment on tidal current energy resources mainly refers to the two tasks in the special fund MCIAC, which named as "Study on Marine Renewable Energy in Coastal Region of China" and "The Prospect Assessment on Utilization of Renewable Energy Resources in China". The basic data provided by tidal simulation technology was used in this work to estimate the tidal current energy resources in the main channels in China. The potential amount of tidal current energy from the assessment of these two tasks is about $0.833 \mathrm{GW}$ while the exploitable amount is $0.166 \mathrm{GW}$. As shown in Fig. 1, the plentiful resources are mainly distributed in Bohai Strait, channels of Zhoushan archipelago, mouths of Fujian bay, Qiongzhou Strait etc.

The third large-scale assessment on tidal current energy resources was financially supported by one of ocean special fund project "Exploration and Selection of the Exploitation and Utilization Area of Tidal Range Energy and Tidal Current Energy in China" [43]. The project adopted FVCOM model to make a more meticulous assessment on 10 relatively prospective coastal regions on the basis of the former two general surveys and assessments. The horizontal spatial resolution of the model is superior to $100 \mathrm{~m}$, and the data from more than 50 measurement stations of tidal current have been applied to verify the numerical model. For the assessment, "effective flow duration" and other factors reflecting the temporal characteristics of tidal current energy resources were also put forward. This assessment is more pertinent/valuable in site selection compared to the 1st and 2nd large-scale assessment, and is more advanced and scientific in the aspects of survey method, data analysis, the evaluation method, etc. The result shows that: the theoretical potential of tidal current energy resources in 75 water channel sections of 10 main regions including Bohai Strait, outside of Chengshan Cape, Jiaozhou Bay, Zhaitang Channel, Yangtze Estuary, Hangzhou Bay, Zhoushan Sea Area, Sansha Bay, Jinmen Channel, Qiongzhou Strait are about $0.556 \mathrm{GW}$. The area of different Prior Developing Level (PDL) of tidal current energy has been computed used ArcGIS software. The area of above Class III (Table 2) is about $13670.7 \mathrm{~km}^{2}$, accounting for $98.4 \%$ of the total assessed region [44]; and the area of Class II is about $183.6 \mathrm{~km}^{2}$, accounting for $1.3 \%$ while the area of Class I is only $36.6 \mathrm{~km}^{2}$, accounting for $0.3 \%$.

TABLE II. ZONING LEVEL OF TIDAL CURRENT ENERGY RESOURCES IN COASTAL REGIONS OF CHINA

\begin{tabular}{|l|l|l|l|l|}
\hline \multicolumn{1}{|c|}{ Zoning level } & \multicolumn{1}{|c|}{$\begin{array}{c}\text { Rich region } \\
\text { (Area of class I) }\end{array}$} & $\begin{array}{l}\text { Relatively rich } \\
\text { region (Area of } \\
\text { class II) }\end{array}$ & $\begin{array}{c}\text { Exploitable } \\
\text { area (Area of } \\
\text { class III) }\end{array}$ & $\begin{array}{c}\text { Scarce area } \\
\text { (Area of class } \\
\text { IV) }\end{array}$ \\
\hline Zoning category and No. & 1 & 2 & 3 & 4 \\
\hline $\begin{array}{l}\text { Average power density of spring tide } \\
(\mathrm{P}) /\left(\mathrm{kW} / \mathrm{m}^{2}\right)\end{array}$ & $\mathrm{P} \geq 8$ & $8>\mathrm{P} \geq 4$ & $4>\mathrm{P} \geq 0.8$ & $\mathrm{P}<0.8$ \\
\hline $\begin{array}{l}\text { Reference value of maximum flow velocity }(\mathrm{V}) \\
/(\mathrm{m} / \mathrm{s})\end{array}$ & $\mathrm{V} \geq 2.5$ & $2.5>\mathrm{V} \geq 2$ & $2>\mathrm{V} \geq 1.2$ & $\mathrm{~V}<1.2$ \\
\hline
\end{tabular}

What needs to point out is that the above statistical conclusion only represents the amount of tidal current energy resources of partial channels of China with a certain extent prospects for exploitation, and it does not represent the total gross of tidal current energy resources of Chinese coastal region. With the assessment work deepened, especially the further decrease of the start-up current speed of turbine motor, the exploitable area with tidal current energy resources will be further increased, and the corresponding total amount of tidal current energy resources is also bound to increase.

\section{CONCLUSION}

Marine renewable energy sources, one class of the important strategic energy sources, are of great significance for energy supply of offshore islands and cannot be non-negligible. Especially, tidal current energy are one kind with great potential and extensive utilization prospect. In the past decades, much efforts have been made to understand the distribution of tidal current energy and wave energy along the Chinese coast. At present, financial support and the making of corresponding incentive policies for marine energy should be enhanced continuously, which can facilitate to promote technical research and to formulate related industries for development of marine energy of China.

At present, further serious variations of coastline and bathymetry make relatively dramatic change of the spatial distribution of marine energy resource because of the construction of coastal reclamation and ocean engineering in recent years. The assessment and investigation needs to be further updated or expanded to provide bases for the planning layout and design of power station of marine energy. From the beginning of this century, although relatively large-scale assessment on marine energy was carried out for twice, i.e. the funds MCIAC and MESF, and the basic characteristics and distributions of tidal current energy and wave energy have been grasped for the main objective "selecting a batch of areas for development of marine energy". However, the needs for the design of demonstration project and large-scale development of marine energy cannot be met yet. Therefore, some special surveys and studies are still needed for selecting proper stations for deployment of marine energy device, for precisely describing the characteristics of marine energy before and after the deployment of turbines, for optimizing the layout of large-scale array through combining natural and social environmental information and policies and 
regulations of Marine Functional Zoning (MFZ), for advancing the assessment standards and technical specifications, for providing full and accurate information for the (pre-)feasibility study and detailed engineering design of power station of marine energy.

\section{ACKNOWLEDGEMENT}

This study is financially supported by the Chinese Marine Renewable Energy Special Fund (GHME2013GC03, GHME2013ZC01, GHME2014ZC01).

\section{REFERENCES}

[1] The Executive Committee of Ocean Energy Systems, 2013 Annual Report. 2013, pp. 39-131

[2] International Renewable Energy Agency, Ocean Energy technology readiness, patents, deployment status and outlook, 2014, pp. 9-12.

[3] X.G. Lv and F.L Qiao, Advances in Study on Tidal Current Energy Resource Assessment Methods. Advances in Marine Science. 2008, 26, pp. 98-108

[4] J.X. Han, Chinese Marginal Seas - Ocean renewable energy. 2015

[5] C.K. Wang and W.Y Shi,. The Evaluation of Ocean Energy Resource in China. Proceedings of the Fourteenth National Symposium on Maritime Technology, Xiamen. 2009, pp. 1-9.

[6] F. Hou, H.M. Yu, X.W. Bao and H Wu, Analysis of Tidal Current Energy in Zhousha Sea Area Based on High Resolution Numerical Modeling. Acta Energiae Solaris Sinica. 2014, 35, pp. 125-133.

[7] X.P. Xun, Chinese Regional Sea. China Ocean Press. 2006.

[8] C.K. Wang and W. Lu, The analytical methods and reserves estimation of Ocean Energy Resource. China Ocean Press. 2009

[9] X.Y. Luo and D.W. Xia, Strategic Research on Development and Utilization of Marine Renewable Energy. 2014.

[10] C. Legrand, Assessment of Tidal Energy Resource. European Marine Energy Centre Ltd. 2009.

[11] Commission, I.E. Technical Specification Marine energy - Wave, tidal and other water current converters. Tidal energy resource assessment and characterization. 2015,201.

[12] G.R. Kuang and D.J Zhou, Preliminary Assessment of Tidal Current Energy on Chengshanjiao. Ocean Thechnology. 19876, X. pp. $44-48$
[13] Z.N. Zheng, The Estimation of Tidal Current Energy. Marine Science Bulletin. 1987, 6, pp. 70-75.

[14] H. Wu,; S.M. Zhao, H.F. Xu and Z.H. Zhang, Preliminary Assessment of Tidal Current Energy on Chengshantou Area. Ocean Thechnology. 2010, 29, pp. 98-100.

[15] S.J. He, Tidal Current Characteristics and Energy Parameters in Zhoushan Islands. Energy Engineering. 1982.

[16] Z.F. Wang, L.M. Zhou, G.B. Zhang and A.F. Wang, Tidal Stream Energy Assessment in Specific Channels of Zhoushan Sea Area. Periodical of Ocean University of China. 2010, 40, pp. 27-33.

[17] X.G. Lv, F.L. Qiao, C. Zhao and C.S. Xia, Numerical Evaluation of Tidal Stream Energy Resources in the Ocean: A Case Study in Jiaozhou Bay Mouth. Acta Energier Solaris Sinica. 2010, 31, pp. 137-143.

[18] H.Wu, S.M. Zhao, S. Zhang, X. Wang and Z.Z. Ma, Preliminary assessment of tidal energy in Lao Tieshan channel. Marine Science Bulletin. 2011, 30, pp. 310-314.

[19] L.Y. Wu, X. Wang and X.J. Xiong, Assessment of Tidal Stream Energy in the Bohai Strait Using A High Resolution Model. Advances in Marine science. 2013, 31, pp. 12-21.

[20] J.R. Chen, Characteristic analysis of tidal current energy in the Xiamen Bay and Jinmen channel, Marine Science Bulletin. 2013, pp. 641-647.

[21] H. Wu, H.M. Yu, J. Ding and D.K. Yuan, Modeling assessment of tidal current energy in the Qiongzhou. Acta Oceanol. Sin. 2016, 35, pp. 21-29.

[22] Communities, C.o.t.E. The Exploitation of tidal and Marine Currents. Program JOULE II, technical report. 1996.

[23] Black UK, V.C.L. Europe, and global tidal energy resource assessment. M.E.C. Report (Ed.), London, 2004.

[24] C. Garrett and P. Cummins, Generating power from tidal currents. Coastal, Ocean Eng. 2004, 130, pp. 114-118.

[25] C. Garrett and P. Cummins, The power potential of tidal currents in channels. Proc. R. Soc. A. 2005, pp. 461-2563.

[26] R. Vennell, Estimating the power potential of tidal currents and the impact of power extraction on flow speeds. Renewable Energy. 2011,36, pp. 3558-3565.

[27] R. Vennell, Realizing the potential of tidal currents and the efficiency of turbine farms in a channel. Renewable Energy. 2012, 47, pp. 95-102.

[28] R. Vennell, S.W. Funke, S. Draper, C. Stevens and T. Divett, Designing large arrays of tidal turbines: A synthesis and review, Renewable and Sustainable Energy Reviews. 2015, 41, pp. 454472. 